\title{
Length of Stay in the Emergency Department and Its Associated Factors at Jimma Medical Center, Southwest Ethiopia
}

This article was published in the following Dove Press journal: Open Access Emergency Medicine

\author{
Abdulwahid Awol Ahmed (iD) \\ Shemsedin Amme lbro (iD) \\ Gemechis Melkamu \\ Sheka Shemsi Seid (D) \\ Temamen Tesfaye (D) ${ }^{\prime}$ \\ 'School of Nursing and Midwifery, Jimma \\ University, Jimma, Oromia Region, \\ Ethiopia; ${ }^{2}$ School of Medicine, Jimma \\ University, Jimma, Oromia Region, \\ Ethiopia
}

Background: Prolonged emergency department stays can adversely affect patient outcomes leading to an increased length of hospital admission and higher mortality. Despite this fact, there are few data describing emergency department length of stay and associated factors in Ethiopia.

Objective: To assess length of stay in the emergency department and its associated factors among patients visited adult emergency department of Jimma Medical Center, Jimma town, southwest of Ethiopia.

Methods: Institution-based cross-sectional study was conducted from April 9, 2018 to May 11, 2018. Overall, 422 patients presented during study period were sequentially included in the study. A semi-structured questionnaire was used to collect data through interview, observation and medical record review. The collected data were cleaned, entered to Epi-data 3.1 and exported to SPSS version 21 for binary and multivariable logistic regression analysis. To identify factors associated with outcome variable, candidate variables were fitted to multivariable analysis, and those with $P$-values $<0.05$ were considered as significantly associated.

Results: More than one-third, 162 (38.4\%), experienced prolonged length of stay in the emergency department. The odds of prolonged stay were higher among rural area residency (AOR, 3.0; CI, 1.279-7.042), evening presentation (AOR, 4.25; CI, 1.742-10.417), and night-time presentation (AOR, 14.93; CI, 4.22-52.63), and having at least one diagnostic investigation (AOR, 4.48; CI, 1.69-11.88). However, participants who did not experience shift changes of nurses during their stay (AOR, 0.003; CI, 0.001-0.010) had a less prolonged stay.

Conclusion: A significant proportion of patients experienced a prolonged stay at the emergency department. Age, rural residency, evening and night-time presentation, shift change and having a diagnostic investigation were predictors of prolonged stay. Thus, establishing time-targeted service for patients can reduce the length of stay.

Keywords: emergency department, length of stay, prolonged stay

\section{Introduction}

The emergency department (ED) is a 24-hours location serving an unscheduled patient population with anticipated needs for emergency care. It represents the "front door" to the province of the health care system for many patients, which represents about three-fifths of inpatient hospital admissions. ${ }^{1,2}$ Emergency department length of stay (ED LOS) starts from entrance to the unit and does 
not end until the patient is either discharged home, admitted to hospital or transferred to another institution. This time period indicates how well an ED is working and performing. ${ }^{1}$

Varies studies ${ }^{3,4}$ defined prolonged ED LOS as a length of stay of more than 6 hours at the ED; it is used as a performance indicator to assess the quality of care in the $\mathrm{ED},{ }^{5}$ and evidence suggests that ED LOS of more than 6 hours is associated with increased mortality. ${ }^{3}$

Worldwide, there is an increasing demand for hospital ED visits. ${ }^{6,7}$ Visits to the ED rose by $65 \%$ from 2001 and $2011,{ }^{8}$ resulting in increased waiting times, prolonged stays, overcrowding, and delayed admission. ${ }^{9}$ Increased LOS in the ED may leads to crucial costs and may have implications on patient safety and is also associated with hospital occupancy rate. ${ }^{10}$ Prolonged ED stays can adversely affect patient outcomes, ${ }^{11,12}$ leading to increased length of hospital admission, higher inpatient cost, and mortality. $^{13-15}$

Evidence has revealed that prolonged ED stays leads to an estimated $15 \%-30 \%$ higher rate of mortality ${ }^{7,16-18}$ and is also viewed as an evidence of poor hospital performance. ${ }^{19}$ Prolonged stay in the ED is an independent risk factor for pneumonia and each hour increases the risk by approximately $20 \%{ }^{20}$ Mortality rate increased from $2.5 \%$ to $4.5 \%$ with increasing LOS less than 2 hours to 12 hours or more. ${ }^{15}$ With this many consequences of a prolonged stay, it is also a global challenge. For instance, more than half (58.9\%) of respondents in Canada and about $10.2 \%$ in Iran experienced prolonged stays in the ED. ${ }^{3,21}$

Possible causes for prolonged stays have been mentioned in different studies. They may arise both from professionals' inability to perfectly triage patients and limited capacity of the system. ${ }^{22}$ Health care utilization such as laboratory or imaging tests, specialty consultations and admissions, increased from the non-urgent to emergent case in the ED, but there is variability in ED LOS. $^{23}$

The increased demand for emergency department and prolonged ED stay had a negative impact on quality care and patient outcome. Despite this, there is a paucity of data describing ED LOS and associated factors in Africa, particularly in Ethiopia. Therefore, this study aimed to assess ED LOS and associated factors among patients visiting the adult ED of Jimma Medical Center. Such data would help to design evidence-based problemsolving mechanisms.

\section{Methods and Materials}

\section{Study Design and Settings}

An institutional-based cross-sectional study was conducted at the adult ED of Jimma Medical Center (JMC) from April 9, 2018 to May 11, 2018. JMC is located in Jimma town, $352 \mathrm{~km}$ southwest of the Ethiopian capital, Addis Ababa. Currently, JMC is the only teaching referral hospital in the southwest part of Ethiopia. In addition, JMC is the only hospital with a formally organized emergency department in the area, and the department is one of the youngest units, which was recently promoted from an emergency room rendered under outpatient department services. The department serves as an intake unit and inpatient admission unit for critically ill patients. Currently, the ED is staffed with nurses, emergency physicians and emergency and trauma practitioner nurses. On average, about 11,964 and 997 patients visit adult ED annually and monthly, respectively.

\section{Population}

Study population: All patients presented to the ED during the study period were consecutively included in the study.

\section{Eligibility Criteria}

Patients less than 18 years of age and those who are unable to give their consent due to inability to speak or altered mentation where no available accommodating attendants were excluded.

\section{Sample Size and Sampling Procedure}

A single population proportion formula was used to determine sample size, considering $50 \%$ proportion of prolonged stay, a confidence interval of $95 \%$, and a margin of error of $5 \%$. Thus, considering a $10 \%$ of non-response rate, the final calculated sample size was 422 . All patients presented to the ED were sequentially enrolled in the study until the desired sample size was reached; thus, the arrival of the patients at ED was assumed to be randomly occurring.

\section{Variables}

The dependent variable was the status of ED LOS. Independent variables were factors categorized under three categories. Specifically, socio-demographic factors were Age, Sex, Address, Marital status, Educational status, Occupation. In addition, factors related to presentation and clinical characteristics include: Mode of arrival, Onset characteristic, Mental status, Triage level, Diagnosis, and 
Comorbid illness. Organizational factors were: Presentation time, Day of the week, Care received in the ED, Diagnostic investigation, Shift changes, Time of initial intervention and Disposition.

\section{Data Collection Tools and Procedure}

A semi-structured interviewer-administered questionnaire that was developed through a review of published literatures $3,5,6,10,11,13-15,19,21,22,24,25$ based on the objectives of the study was used to collect data and medical records were also reviewed. The questionnaire contains 32 items organized under the aforementioned four major parts. Eight data collectors and one supervisor were employed among BSc-qualified nurses and supervised by the principal investigator. Its face validity was confirmed by a team of experts in emergency medicine, emergency physician and emergency nurses.

Data were collected from the patients following presentation, admission and prior to discharge from the ED through respondent interview, observation and medical recordreview. The data collection procedure is illustrated as follows: first, eligible patients were identified by data collectors at the triage room while resident staff were triaging patients on arrival. Hence at arrival, time and other presentation characteristics were recorded at the triage room. Following this, other information such as socio-demographic characteristics and other organizational-related factors were obtained at interviews, chart review and observation of patients at different treatment points, and after patient gate stabilized otherwise. Finally, information such as diagnostic investigations and overall treatments done were recorded from medical records, whereas overall length of stay at the department and final disposition were recorded right before the patient was discharged from the ED. Hence, essential time-related factors were ED arrival time and the overall length of stay between presentation and discharge from ED.

\section{Data Processing and Analysis Plan}

The collected data were checked for completeness, consistency and accuracy. Data were coded, entered and cleaned using Epi-data 3.1 and exported to SPSS version 21 for analysis. Descriptive statistics were done to summarize the background characteristics of study participants. The overall length of stay was dichotomized ED LOS $\leq 6$ hours and $>6$ hours, then binary logistic regression was done to determine candidate variables for multivariable logistic regression at $P$-values $\leq 0.25$. Then, in multivariable logistic regression analysis, factors significantly associated with outcome variable were identified at $P$-values less than 0.05 and adjusted odds ratios at $95 \% \mathrm{CI}$. Model fitness was checked by Hosmer-Lemeshow goodness of fit $(P=0.21)$. A multicollinearity test was done $(\mathrm{SE}<2.0)$.

\section{Data Quality Assurance}

To insure quality of data, supervisor and data collectors were trained for one day. The questionnaire was translated to local languages (Afaan Oromo and Amharic) by language experts, and then backtranslated into English by anindependent translator to ensure consistency. Translated questionnaire versions were discussed by the team of the Mega-project to identify and resolve inadequate expressions/concepts of translation and alternatives were suggested. The final versions of the questionnaire were pretested on $10 \%$ of the sample at JMC two weeks prior to actual data collection to ensure reliability and necessary modifications were made. On-site close supervision was carried out by a supervisor and the principal investigator to supervise the data collection process and to ensure the completeness and consistency of the filled questionnaire on a daily basis. Further, consistency and completeness of data were throughout data entry and cleaning process.

\section{Ethical Consideration}

Ethical clearance was obtained from Jimma University Institute of Health IRB on January 25, 2018, with reference number IHRPGD/353/2018. An official letter was given to $\mathrm{JMC}$ administration and permission to continue with data collection was obtained. The informed verbal consent process was approved by the Jimma University Institute of Health Institutional Review Board, and this study was conducted in accordance with the Declaration of Helsinki. The study participants explained the study objectives and the right to withdraw at any point. The participation of the respondents was on the basis of voluntary participation. To maintain confidentiality and anonymity of data, they were re-coded upon entry.

\section{Results}

A total of 422 patients with a response rate of $100 \%$ participated in the study. 


\section{Socio-Demographic Characteristics}

The mean age of the participants was $33.1 \pm 16.4$ years. More than half $(233,55.2 \%)$ of participants were male; approximately half $(218,51.7 \%)$ of respondents were married, 304 (72.0\%) were from Oromo by ethnicity, and 257 (60.9\%) were Muslim. About two-thirds $(280,66.4 \%)$ of the respondents were residents of Jimma town. The majority (297, $70.4 \%$ ) of the respondents attended formal education. Nearly one-third $(135,32.0 \%)$ of respondents were students, whereas $120(28.4 \%)$ were farmers (Table 1).

\section{Presenting Characteristics}

A commercial taxi was the mode of arrival to ED for about $153(36.3 \%)$ of the patients; those arriving by ambulance accounted for 94 (22.3\%). Medical conditions were the leading causes of presentation and accounted for 183 (43.4\%), followed by injuries 136 (32.2\%). Infectious diseases accounted for the fewest causes of ED visits (103, $24.4)$. The majority $(351,83.2 \%)$ of the patients presented with a single diagnosis.

The acuity level of presentation on triage was observed; the proportion of patients triaged as higher acuity of red and orange category were $17(4.0 \%)$ and 43 $(10.2 \%)$, respectively. The majority $(374,88.6 \%)$ of the respondents were fully alert on arrival to the ED (Table 2).

\section{Presentation Time and ED-Related}

\section{Characteristics}

The majority of the respondents presented to the ED during daytime, specifically 181 (42.9\%) arrived during the morning, while 171 (40.5\%) presented during the evening. Furthermore, $340(80.6 \%)$ respondents presented during working weekdays. The majority of respondents (357, $84.6 \%$ ) received care while at the ED. Similarly, the majority $(329,78.0 \%)$ had at least one diagnostic investigation; 129 (30.6\%) had laboratory tests and 293 (69.4\%) underwent at least one imaging study. Respondents who experienced shift changes of nurses during their stay at ED accounted for $183(43.4 \%)$. A quarter $(105,24.9 \%)$ of patients were admitted to an inpatient unit; where the majority $(315,74.6 \%)$ were discharged and $2(0.5 \%)$ were transferred to other facilities (Table 3).
Table I Socio-Demographic Characteristics of Patients Who Visited The Adult ED of JMC, Jimma Town, Oromia Region, SouthWest of Ethiopia, $2018(n=422)$

\begin{tabular}{|c|c|c|}
\hline Characteristics & Number (No.) & Percentage (\%) \\
\hline Total visits & 422 & 100 \\
\hline \multicolumn{3}{|l|}{ Age } \\
\hline 18-29 years & 240 & 56.9 \\
\hline 30-39 years & 62 & 14.7 \\
\hline $40-59$ years & 71 & 16.8 \\
\hline 60-69 years & 26 & 6.2 \\
\hline $70+$ years & 23 & 5.5 \\
\hline \multicolumn{3}{|l|}{ Sex } \\
\hline Female & 189 & 44.8 \\
\hline Male & 233 & 55.2 \\
\hline \multicolumn{3}{|l|}{ Address } \\
\hline Rural & 142 & 33.6 \\
\hline Urban & 280 & 66.4 \\
\hline \multicolumn{3}{|l|}{ Marital status } \\
\hline Married & 218 & 51.7 \\
\hline Single & 194 & 46.0 \\
\hline Other $^{\mathrm{a}}$ & 10 & 2.4 \\
\hline \multicolumn{3}{|l|}{ Religion } \\
\hline Muslim & 257 & 60.9 \\
\hline Orthodox & 106 & 25.1 \\
\hline Protestant & 58 & 13.7 \\
\hline Catholic & 1 & 0.2 \\
\hline \multicolumn{3}{|l|}{ Ethnicity } \\
\hline Oromo & 304 & 72.0 \\
\hline Amhara & 63 & 14.9 \\
\hline Dawaro & 26 & 6.2 \\
\hline Other $^{b}$ & 29 & 6.9 \\
\hline \multicolumn{3}{|l|}{ Literacy status } \\
\hline Illiterate & 95 & 22.5 \\
\hline Read and write & 30 & 7.1 \\
\hline Secondary school & 94 & 22.3 \\
\hline University/college & 84 & 19.9 \\
\hline Primary school & 119 & 28.2 \\
\hline \multicolumn{3}{|l|}{ Occupation } \\
\hline Farmer & 120 & 28.4 \\
\hline Daily labor & 32 & 7.6 \\
\hline Employees & 44 & 10.4 \\
\hline Merchant & 66 & 15.6 \\
\hline Student & 135 & 32.0 \\
\hline Other & 25 & 5.9 \\
\hline
\end{tabular}

Notes: ${ }^{a}$ Divorced, widowed, separated; ' $\mathrm{G}$ urage, Gambela, Kefa, Kambata, Silte, Tigre; 'Housewife, unemployed. 
Table 2 Presenting Characteristics of Patients Who Visited The Adult ED of JMC, Jimma Town, Oromia Region, Southwest of Ethiopia, $2018(n=422)$

\begin{tabular}{|c|c|c|}
\hline Factors & Number & Percent \\
\hline \multicolumn{3}{|l|}{ Mode of arrival } \\
\hline By taxi & 153 & 36.3 \\
\hline By ambulance & 94 & 22.3 \\
\hline By public car/track & 94 & 22.3 \\
\hline By foot & 75 & 17.8 \\
\hline Other ${ }^{a}$ & 6 & 1.4 \\
\hline \multicolumn{3}{|l|}{ Main primary diagnosis category } \\
\hline Medical conditions & 183 & 43.4 \\
\hline Infectious illness & 103 & 24.4 \\
\hline Injuries & 136 & 32.2 \\
\hline \multicolumn{3}{|l|}{ Presence of Comorbid Illness } \\
\hline Yes & 72 & I7.I \\
\hline No & 350 & 82.9 \\
\hline \multicolumn{3}{|l|}{ Triage Category } \\
\hline $\operatorname{Red}^{\mathrm{b}}$ & 17 & 4.0 \\
\hline Orange $^{c}$ & 43 & 10.2 \\
\hline Yellow $^{d}$ & 190 & 45.0 \\
\hline Green $^{\mathrm{e}}$ & 172 & 40.8 \\
\hline \multicolumn{3}{|l|}{ Mental status } \\
\hline Fully alert & 374 & 88.6 \\
\hline Comatose & 9 & 2.1 \\
\hline Confused & 39 & 9.2 \\
\hline
\end{tabular}

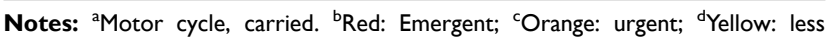
urgent; ${ }^{\mathrm{e}} \mathrm{Green}$ : non-urgent.

\section{ED Length of Stay}

The median (IQR) ED length of stay among the respondents was $4(1.6-13.5)$ hours. More than onethird $(162,38.4 \%)$ of patients experienced a prolonged stay at the ED. The rest $(260,61.6 \%)$ were discharged from the ED within 6 hours.

\section{Reason for Prolonged ED LOS from Respondent's Perspective}

The reasons for prolonged ED LOS among respondents who experienced a prolonged stay were waiting for results of investigation, waiting for specialist consultation, and absence of an inpatient bed, which accounts for 80 (49.4\%), 62 (38.3\%) and 31 (19.1\%), respectively.

\section{Factors Associated with Prolonged Emergency Department Length of Stay}

In the bivariate analysis, age, address, marital status, educational status, occupation, triage category, most
Table 3 Presentation Time and ED-Related Factors Among Patients Who Visited The Adult ED of JMC, Jimma Town, Oromia Region, Southwest of Ethiopia, $2018(n=422)$

\begin{tabular}{|l|l|l|}
\hline Factors & Number & Percent \\
\hline Time of the day & & \\
Morning & 181 & 42.9 \\
Evening & 171 & 40.5 \\
Night & 70 & 16.6 \\
\hline Day of the week & & \\
Weekday & 340 & 80.6 \\
Weekend & 82 & 19.4 \\
\hline Received any intervention in the ED & & \\
Yes & 357 & 84.6 \\
No & 65 & 15.4 \\
\hline Having at least one diagnostic investigation & & \\
Yes & 329 & 78.0 \\
No & 93 & 22.0 \\
\hline Laboratory tests & & \\
Yes & 293 & 69.4 \\
No & 129 & 30.6 \\
\hline Imaging studies & & \\
Yes & 147 & 34.8 \\
No & 275 & 65.2 \\
\hline Shift change experience & & \\
Yes & 239 & 53.4 \\
No & 25.6 \\
\hline Discharge from ED & & \\
Admitted & & \\
Discharged & & \\
Transferred & & \\
\hline
\end{tabular}

responsible diagnosis, mental status, presentation time, time of initial intervention, having at least one investigation and shift change of nurse were found to be significantly associated with a prolonged stay in the ED.

In multivariable logistic regression analysis the following independent predictors of ED LOS $>6 \mathrm{~h}$ were identified: age, residency address, mental status, day of week, time of day, diagnostic investigation, and experiencing nurses' shift change.

The odds of prolonged stay at ED among respondents of age 40-59 years were 5.4 times (AOR, 5.38; CI, 1.81-15.87) higher than those of 18-29 years. Patients from rural areas were three times (AOR, 3.00; CI, 1.279-7.042) more likely to have an ED LOS more than 6 hours than were urban residents. 
Table 4 Multivariable Analysis of Factors Associated with ED Length of Stay Among Patients Who Visited The Adult ED of JMC, Jimma Town, Oromia Region, Southwest of Ethiopia, 2018

\begin{tabular}{|c|c|c|c|c|}
\hline \multirow[t]{2}{*}{ Factors } & \multicolumn{2}{|c|}{ ED Length of Stay No. (\%) } & \multirow[t]{2}{*}{ COR $(95 \% \mathrm{Cl})$} & \multirow[t]{2}{*}{ AOR (95\% Cl) } \\
\hline & Prolonged & Not Prolonged & & \\
\hline \multicolumn{5}{|l|}{ Age } \\
\hline $18-29$ years & $73(17.3)$ & $167(39.6)$ & 1 & 1 \\
\hline $30-39$ years & $22(5.2)$ & $40(9.5)$ & $1.26(0.70-2.27)$ & $0.55(0.20-1.53)$ \\
\hline $40-59$ years & $39(9.2)$ & $32(7.6)$ & $2.79(1.62-4.78)$ & $5.38(1.8 \mathrm{I}-15.87)^{\mathrm{b}}$ \\
\hline $60-69$ years & $18(4.3)$ & $8(1.9)$ & $5.15(2.14-12.35)$ & $4.52(0.82-25.00)$ \\
\hline $70+$ years & $10(2.4)$ & $13(3.1)$ & $1.76(0.74-4.20)$ & $0.97(0.24-3.97)$ \\
\hline \multicolumn{5}{|l|}{ Address } \\
\hline Rural & 71 (16.8) & 71 (16.8) & $2.08(1.37-3.14)$ & $3.0(1.28-7.04)^{b}$ \\
\hline Urban & $91(21.6)$ & $189(44.8)$ & I & 1 \\
\hline \multicolumn{5}{|l|}{ Mental status } \\
\hline Fully alert & $134(3 \mid .8)$ & $240(56.9)$ & 1 & 1 \\
\hline Confused & $5(1.2)$ & $4(0.9)$ & $2.24(0.59-8.47)$ & $8.20(2.05-32.26)^{b}$ \\
\hline Comatose & $23(5.5)$ & $16(3.8)$ & $2.58(1.31-5.05)$ & $3.38(0.32-35.7 I)$ \\
\hline \multicolumn{5}{|l|}{ Time of the day } \\
\hline Morning & $57(13.5)$ & $124(29.4)$ & 1 & 1 \\
\hline Evening & $74(17.5)$ & $97(23.0)$ & $1.66(1.07-2.56)$ & $4.26(1.74-10.42)^{c}$ \\
\hline Night & $31(7.3)$ & $39(9.2)$ & $1.73(0.98-3.05)$ & $14.93(4.22-52.63)^{c}$ \\
\hline \multicolumn{5}{|l|}{ Day of the week } \\
\hline Weekday & $136(32.2)$ & $204(48.3)$ & I.44 (0.86-2.40) & $2.59(1.0 \mathrm{I}-6.64)^{\mathrm{a}}$ \\
\hline Weekend & $26(6.2)$ & $56(13.3)$ & I & 1 \\
\hline \multicolumn{5}{|c|}{ Diagnostic investigation } \\
\hline Yes & $144(34.1)$ & $185(43.8)$ & $3.24(1.86-5.67)$ & $4.48(1.69-11.88)^{b}$ \\
\hline No & $18(4.3)$ & $75(17.8)$ & 1 & 1 \\
\hline \multicolumn{5}{|l|}{ Shift change } \\
\hline Yes & $150(35.5)$ & $33(7.8)$ & 1 & 1 \\
\hline No & $12(2.8)$ & $227(53.8)$ & $0.01(0.01-0.02)$ & $0.003(0.00 \mathrm{I}-0.0 \mathrm{I} 0)^{\mathrm{c}}$ \\
\hline
\end{tabular}

Notes: ${ }^{\text {a }} P$-value $<0.05 ;{ }^{b} P$-value $<0.03 ;{ }^{C} P$-value $<0.001$.

Abbreviations: $\mathrm{COR}$, crude odds ratio; $\mathrm{AOR}$, adjusted odds ratio; $\mathrm{Cl}$, confidence interval.

The odds of a prolonged stay at the ED among respondents who presented with confused mentation were 8.2 times (AOR, 8.20; CI, 2.05-32.26) higher than those fully conscious on presentation. An evening presentation was 4.3 times (AOR, 4.25; CI, 1.74-10.42) more likely to have a prolonged stay than a morning presentation, while night-time presentation was 14.9 times (AOR, 14.93; CI, 4.22-52.63) more likely to have prolonged stay than a morning presentation. Furthermore, the odds of experiencing a prolonged stay at the ED among those presenting during weekdays were 2.6 times (AOR, 2.59; CI, 1.01-6.64) higher than those who presented at the weekend. The odds of experiencing a prolonged stay at the ED among those having at least one diagnostic investigation were 4.5 times (AOR, 4.48; CI, 1.69-11.88) higher than those having no any diagnostic investigation. Furthermore, those who did not experience a shift change of nurses during their stay were about $99.7 \%$ (AOR, 0.003; CI, 0.001-0.01) less likely to have a prolonged ED LOS than those experiencing shift changes of nurses during their stay in the ED (Table 4).

\section{Discussion}

The emergency department (ED) represents the "front door" to the province of the health care system for many patients, which starts from entrance to the unit and does not end until the patient is either discharged home, admitted to hospital or transferred to another institution. The patient's length of stay is a major indicator reflecting how well an ED is working, and the overall efficiency and quality service of an ED. ${ }^{1,26}$ The level of emergency 
department length of stay (ED LOS) is context-based and varies from country to country. The present study assessed the level of patients' length of stay at ED and associated factors with prolonged stay at ED of JMC, southwest of Ethiopia.

The median (IQR) ED length of stay was 4 (1.6-13.5) hours, which is lower than the median LOS reported by an international study done in Switzerland, France and the United States, which was 5.5 (5.1-5.6) hours, ${ }^{24}$ and about twofold lower than the finding of a study conducted in Ontario, Canada, which was 7 (4-13) hours. ${ }^{3}$ The differences may be attributed to differences in size of the study population, the high proportion of non-urgent cases observed in the present study, and the difference in health care system level of advancements. Usually non-urgent cases would stay at the ED for a shorter period of time, and unlike our emergency medical care, a well-developed emergency medical system in the western world, non-urgent patients would be exempted from visiting the ED or traced out on arrival.

According to the findings of the present study, 38.4\% of patients experienced a prolonged stay in the ED, which was relatively lower than prior study conducted in Canada, ${ }^{3}$ Saudi Arabia, ${ }^{13}$ while higher than a study done in Iran. ${ }^{21}$ This discrepancy may be due to the difference in study design; sample size, variation in presenting characteristics of patient those visiting emergency department. More than half of patients $(61.6 \%)$ had an ED LOS of 6 hours or less. This is consistent with the Canadian Association of Emergency Physician's recommendation, ${ }^{4}$ an internationally recognized performance indicator used to assess the quality of emergency care. ${ }^{5}$

Patients from rural areas were about 3.0 times more likely to have a prolonged stay. In fact, those rural area residents were traveling from increased distances with less access to fast transportation, pre-ED care during transportation and primary care facilities. Therefore, this delay in presentation may contribute to worsening of disease conditions which in turn resulted in increased treatment duration at hospital. Literatures indicating that pre-ED care such as pre-hospital care given to the patients in emergent conditions at the scene and during transportation to hospital can affect treatment outcomes at the ED. ${ }^{27}$

The present study identified that patients who presented during the evening and night-time were more likely to have a prolonged stay than those with a morning presentation. According to the findings of the study conducted in Canada, ${ }^{3}$ ED arrival at night was more likely to have a prolonged stay at ED. The possible explanation could be the fact that the hospital may not admit to inpatient or discharge patients during the night shift; night shift arrivals to ED need to wait until daytime to be admitted or discharged. Thus, this will increase the length of stay at the ED. In addition, expert consultation and diagnostic or therapeutic modalities are less available at night compared to during theday. This explanation may work for possible prolonged stay at ED among patients who presented at the weekend. However, in this study, those who presented during the week were more likely to experience a prolonged stay at the ED than those who presented at the weekend. This may be due to a relatively high proportion of patients visiting on weekdays at the weekend, which were in a five to one ratio. Furthermore, the paradox may be due to the present study design that involved small number of study subjects presented over a short study period. Nevertheless, this discrepancy should be repeated by further studies, and probably further prospective studies explaining the reason behind it will be needed in the future.

Similar to our study finding, a study conducted at an academic hospital in the Netherlands ${ }^{28}$ revealed that patients with altered consciousness had a higher likelihood of a prolonged stay at the ED. This might be due to the complexity of the patient's response with altered mentation to be managed within a short period of time.

Unlike previous studies, ${ }^{23,29}$ a prolonged stay at tge ED was not associated with arrival by ambulance in this facility-based study. This has implications for the interpretation of previous studies, and also for the design of studies to further understand the relationship between level of ED LOS and mode of arrival to the ED. In accordance with the finding of this study, the study conducted in the USA ${ }^{30,31}$ and $\mathrm{Canada}^{23}$ revealed that the use of diagnostic tests and advanced diagnostic imaging (computed tomography, magnetic resonance imaging) were found to be associated with a prolonged ED length of stay.

Similar to this study, a study conducted in Israel $^{10}$ revealed that experience of nurses' shift change appears to be a major factor that has significant influence on ED LOS. This could be due to miscommunication and lack of continuum-of-care which may occur during hand over management. Similarly, the result of a retrospective study conducted in the USA ${ }^{25}$ showed increased LOS among patients experiencing a shift change of nurses during stay in the emergency department.

The strength of this study is that it was the first of its kind in the study area and provided information on ED LOS and associated factors. Further, this study has used different data collection methods including respondent interviews, observation and document review to collect 
subjective and objective data related to patients across the timeline from arrival to discharge.

However, some limitations need to be taken into account. First, this one-month cross-sectional study which was performed at a single academic institution may limit the ability to apply the study conclusions to another hospital with a different patient population. Second, the study design cannot account for possible seasonal variations in disease incidence and, hence, ED patient populations. Lastly, there were also inconsistencies among different literature in the description of ED LOS which limits the ability to compare and appropriately plan. $^{1}$

\section{Conclusions and Recommendations}

The present study identified that significant proportions of patients experienced a prolonged stay in the emergency department. Absence of inpatient beds and waiting for specialist consultations and results of diagnostic investigations were reported reasons for a prolonged stay. Age, rural residency, mentation on presentation, presentation time, days of week, nurse shift change and having diagnostic investigations are factors associated with a prolonged stay at the ED. Administrative initiatives that enhance time-targeted service for patients to be seen, treated and discharged or transferred from the ED without compromising the care given would improve the length of stay at the ED. Therefore, adjusting the ED organization in the way it improves patient length of stay must be taken, facilitating diagnostic services with priority to emergency patients, adjusting human resource and treatment resource allocation and utilization to accommodate gaps during presentation time and shift change. In addition, further studies on the influence of pre-ED care, ED treatment timings, and ED service organization and patient flows on the length of stay, as well as the influence of ED length of stay on hospital outcomes, should be undertaken in the future.

\section{Acknowledgment}

We would like to acknowledge Jimma University for the financial support of the study, study participants and JMC health professionals for their unreserved support for the realization of the study.

\section{Author Contributions}

All authors made substantial contributions to conception and design, acquisition of data, or analysis and interpretation of data; took part in drafting the article or revising it critically for important intellectual content; gave final approval of the version to be published, and agree to be accountable for all aspects of the work.

\section{Funding}

The source of fund for this research work is Research and Postgraduate Director Office, Institute of Health, Jimma University.

\section{Disclosure}

The authors report no conflicts of interest in this work.

\section{References}

1. Sullivan S. A Strategy to Reduce Emergency Department Wait Times in Newfoundland and Labrador. Department of Health and Community services; 2012.

2. Scott GWS, Yeates G, Barrett P, Doiron CA, Eagle C, Empey K Canadian institute for health information report, health indicators. Ottawa, Ontario; 2008.

3. Rose L, Scales DC, Atzema C, et al. Emergency department length of stay for critical care admissions a population-based study. Ann ATS. 2016;13:1325-1332.

4. CAEP. Canadian Association of Emergency Physicians (CAEP). Position statement on emergency overcrowding. 2009.

5. Horwitz LI, Green J, Bradley EH. US emergency department performance on wait time and length of visit. Ann Emerg Med. 2010;55:133-141. doi:10.1016/j.annemergmed.2009.07.023

6. Pines JM, Hilton JA, Weber EJ, et al. International perspectives on emergency department crowding. Acad Emerg Med. 2011;18:1358-1370. doi:10.1111/j.1553-2712.2011.01235.x

7. Forero R, Hillman KM, McCarthy S, Fatovich DM, Joseph AP, Richardson DB. Access block and ED overcrowding. Emerg Med Australas. 2010;22:119-135.

8. McCarthy S. Where Do NEAT and Patient Safety Meet. NSW Emergency Care Institute; 2013.

9. Geelhoed G, Klerk N. Emergency department overcrowding, mortality and the 4-hour rule in Western Australia. Med J Aust. 2012;196 (2):122-126. doi:10.5694/mja11.11159

10. Bashkin O, Caspi S, Haligoa R, Mizrahi S, Stalnikowicz R. Organizational factors affecting length of stay in the emergency department: initial observational study. Isr J Health Policy Res. 2015;4(1):1-7. doi:10.1186/s13584-015-0035-6

11. Sullivan CM, Staib A, Flores J, et al. Aiming to be NEAT: safely improving and sustaining access to emergency care in a tertiary referral hospital. Aust Health Rev. 2014;38(5):564-574. doi:10.1071/AH14083

12. Maumill L, Zic M, Esson AA, et al. The National Emergency Access Target (NEAT): can quality go with timeliness? Med J Aust. 2013;198 (3):153-157. doi:10.5694/mja12.11063

13. Al-Qahtani S, Alsultan A, Haddad S, et al. The association of duration of boarding in the emergency room and the outcome of patients admitted to the intensive care unit. BMC Emerg Med. 2017;17(1). doi:10.1186/s12873-017-0143-4.

14. Chalfin DB, Trzeciak S, Likourezos A, Baumann BM, Dellinger P. Impact of delayed transfer of critically ill patients from the emergency department to the intensive care unit. Crit Care Med. 2007;35 (6):1477. doi:10.1097/01.CCM.0000266585.74905.5A

15. Singer AJ Jr, Thode HC, Viccellio P, Pines JM. The association between length of emergency department boarding and mortality. Acad Emerg Med. 2011;18(12):1324-1329. doi:10.1111/j.15532712.2011.01236.x 
16. Green D. Is national emergency access target dumbing down emergency physicians? Emerg Med Australas. 2014;26(3):305-307. doi:10.1111/1742-6723.12238

17. Mountain D. Introduction of a 4-hour rule in Western Australian emergency departments. Emerg Med Australas. 2010;22 (5):374-378. doi:10.1111/j.1742-6723.2010.01327.x

18. Braitberg G. Emergency department overcrowding: the solution to any problem is a matter of relativity. Med J Aust. 2012;196(2):88-89. doi: $10.5694 / \mathrm{mja} 12.10044$

19. Pitts SR, Vaughns FL, Gautreau MA, Cogdell MW, Meisel Z. A cross-sectional study of emergency department boarding practices in the United States. Acad Emerg Med. 2014;21(5):497-503. doi:10.1111/acem.12375

20. Carr BG, Kaye AJ, Wiebe DJ, Gracias VH, Schwab CW, Reilly PM. Emergency department length of stay: a major risk factor for pneumonia in intubated blunt trauma patients. J Trauma Acute Care Surg. 2007;63:9-12. doi:10.1097/TA.0b013e31805d8f6b

21. Hosseininejad SM, Aminiahidashti H, Pashaei SM, et al. Determinants of prolonged length of stay in the emergency department; a cross-sectional study. Emergency. 2017;5:e53.

22. Harris S, Singer PM, Rowan K, Sanderson C. Delay to admission to critical care and mortality among deteriorating ward patients in UK hospitals: a multicentre, prospective, observational cohort study. Lancet. 2015;385:S40. doi:10.1016/S0140-6736(15)60355-5

23. Yoon P, Steiner I, Reinhardt G. Analysis of factors influencing length of stay in the emergency department. Can $J$ Emerg Med. 2003;5:155-161.

24. Kutz A, Florin J, Hausfater P, et al. Predictors for delayed emergency department care in medical patients with acute infections - an international prospective observational study. PLoS One. 2016;11(5): e0155363. doi:10.1371/journal.pone.0155363
25. Jones EM, Boehme AK, Aysenne A, et al. Prolonged E mergency department length of stay as a predictor of adverse outcomes in patients $\mathrm{w}$ ith intracranial hemorrhage. $J$ Crit Care Med. 2015;2015:1-5. doi:10.1155/2015/526319

26. Choi YF, Wong TW, Lau CC. Triage rapid initial assessment by doctor (TRIAD) improves waiting time and processing time of the emergency department. Emerg Med J. 2006;23:262-265. doi:10.1136/emj.2005.025254

27. Kim S, Shin SD, Ro YS, et al. Effect of emergency medical services use on hospital outcomes of acute hemorrhagic stroke. Prehosp Emerg Care. 2016;20(3):324-332. doi:10.3109/ 10903127.2015 .1102996

28. Hesselink G, Van Den Bogaert M, Akkermans RP, et al. Risk factors for prolonged length os stay of older patients in academic emergency department: a retrospective cohort study. Emerg Med Int. 2019.

29. Crilly J, Keijzers G, Tippett V, et al. Improved outcomes for emergency department patients whose ambulance off-stretcher time is not delayed. Emerg Med Australas. 2015;27(3):216-224. doi:10.1111/ 1742-6723.12399

30. Herring A, Wilper A, Himmelstein DU, et al. Increasing length of stay among adult visits to U.S. Emergency departments, 2001-2005. J Soc Acad Emerg Med. 2009;16(7):609-616. doi:10.1111/j.15532712.2009.00428.x

31. Kocher KE, Meurer WJ, Desmond JS, Nallamothu BK. Effect of testing and treatment on emergency department length of stay using a national database. Acad Emerg Med. 2012;19(5):525-534. doi:10.1111/j.1553-2712.2012.01353.x
Open Access Emergency Medicine

\section{Publish your work in this journal}

The Open Access Emergency Medicine is an international, peerreviewed, open access journal publishing original research, reports, editorials, reviews and commentaries on all aspects of emergency medicine. The manuscript management system is completely online and includes a very quick and fair peer-review system, which is all easy to use. Visit http://www.dovepress.com/testimonials.php to read real quotes from published authors. 